\title{
Title: Emotional intelligence and creative performance: Looking through the lens of environmental uncertainty and cultural intelligence
}

\section{Authors: M. Darvishmotevalia, L. Altinay, G. De Vita}

\begin{abstract}
:
Despite the need to better understand the relationship between employee creativity and emotional intelligence, research remains scant and ambiguous. We examine the effect of emotional intelligence (EI) on frontline employees' creativity and the mediating role of environmental uncertainty (EU) as an explanatory mechanism to understand the EI and creative performance $(\mathrm{CP})$ relationship. In addition, we test for the interaction effect of EI and CI on frontline employees' creativity. Using a sample of 283 frontline employees (FEs) from four and five star hotels, structural equation modeling is employed to test the proposed hypotheses. Results reveal that EI has a positive impact on FEs' creative performance. The findings also confirm the mediating role of EU in the relationship between EI and CP. Moderating regression analyses show that $\mathrm{CI}$ strengthens the impact of $\mathrm{EI}$ on $\mathrm{CP}$, albeit with a marginal increment in explanatory power. Important theoretical and managerial implications flow from our findings.
\end{abstract}

Key words: Creative Performance, Emotional Intelligence, Frontline Employees, Hospitality Industry

\section{INTRODUCTION}

Supporting employee creativity is one of the major human resource challenges for organizations in the 21st century hospitality industry (Chang \& Teng, 2017). This makes the need to understand the relationship between employees' personal ability - emotional and cultural intelligences - and creative performance, acute, especially taking into account the mediating role of environmental uncertainty. The purpose of our study is to address this need. Whilst supporting efforts from organizations in improving employee creativity are widely documented, given our purpose, it is worth emphasizing that recent research highlights that managers in the hospitality industry "face several internal barriers which slow down the proper implementation of creativity principles and make it complicated to grasp the perspective of employees in this context" (Kattara \& El-Said, 2014, p. 140). Hence, the 
purpose of our research endeavor, and its employee personal ability and environment perspectives, are most opportune and timely.

Employees with the ability to "think out of the box" can create a competitive edge for the organization and better deal with the complex challenges and fast changing environment of the modern world (Jafri, Dem, \& Choden, 2016). Due to increasing competition in the hospitality industry, organizations place greater emphasis on creative performance (CP) to maximize customer service quality and satisfaction (Tsai \& Lee, 2014). Creativity leads to the generation of novel and innovative ideas resulting in new product and service development (Tajeddini, Altinay, \& Ratten, 2017). The new products and services developed through creative ideas enable hospitality organizations to respond to the changing needs and wants of the customers and remain highly competitive (Chang \& Teng, 2017).

Given the established significance of employee creativity, it is not surprising that scholars have stressed the need for more in-depth research into the concept of creativity, its association with organizationally desired variables and also the personal and contextual factors which enhance or reduce it (e.g., Kim et al., 2012; State et al., 2014; Tsai et al., 2014). A close examination of the relevant literature delineates a number of potential factors which foster creativity such as ethical leadership and intrinsic motivation (Feng et al., 2016), transformational leadership and creative self-efficacy (Mittal \& Dhar, 2015), proactive personality and responsibility for change (Jiang \& Gu, 2015), and a high level of generosity and vigor (Carmeli et al., 2014). Related literature recognizes several personal characteristics positively related to creativity (Joseph \& Newman, 2010; State et al., 2014), but the antecedents of creativity remain under-researched.

Recently, a handful of studies have focused on the relationship between emotional intelligence (EI) and creativity (Jafri et al., 2016; Tsai \& Lee, 2014; Vratskikh et al., 2016). Nevertheless, the notion of EI is relatively new among hospitality researchers, even though scholars such as Prentice and King (2013) and Sigala and Chalkiti (2015) state that emotional intelligence leads to organizational creativity and better organizational performance. EI refers to the individual's potential for achieving the skills of self-consciousness, self-management, social consciousness, and social management (Goleman, 1998). Despite its importance and relevance, to the authors' knowledge there appears to exist limited research investigating the relationship between EI and the creativity of frontline employees (FEs) in the hospitality industry (Vratskikh et al., 2016). This gap is important becouse as noted by Coelho et al. (2013, p.31), "creative frontline service employees may be crucial in ensuring organizational performance." As a first step to fulfill this gap, this study focused on the effect of EI on FEs' creativity in the hospitality industry.

Existing studies on the relation between EI and creativity have focused more on the direct effect (Tsai \& Lee, 2014), rather than seeking to understand the mechanisms by which EI enhances creative performance or investigating the personality traits which strengthen the above relationship (Vratskikh et al., 2016). Thus, to overcome this gap, we take environmental uncertainty (EU) as an expository mechanism to understand how EI affects frontline employees creativity. Furthermore, this research aims to test the role of cultural intelligence $(\mathrm{CI})$ as a personal ability to moderate the relationship in question. Therefore, the 
study uses creative performance as the final outcome variable and testes the dynamic relations amongst the study variables.

This study has three objectives. Firstly, it examines the effect of EI on the creativity of frontline employees. Secondly, it explores EU as an explanatory mechanism to understand the mentioned relationship. Finally, it tests the interaction effect of EI and CI on frontline employees' creativity (see Fig 1). The results of the study strengthen our understanding of the effect of personal variables (EI and CI) on frontline employees' creativity in the hospitality industry. Moreover, understanding moderation and mediation effects of the chosen constructs on the EI and CP relationship extends our existing knowledge of personal resource and performance outcomes.

This study is one of the few studies in the field of hospitality investigating creative performance. Its importance and novel contribution, lies in demonstrating the link between emotional intelligence and creative performance as emotional intelligence and the management of skills of self-consciousness, self-management, social consciousness, and social management, are crucial for creativity in hospitality organizations (Prentice \& King, 2013). The study also recognizes the dynamic environment in which hospitality organizations operate in their attempts to boost up their creative performance. We are able to explain the relationship between emotional intelligence and creative performance through the lens of environmental uncertainty, a research avenue identified by Tajeddini et al. (2017) in their study of service innovativeness in hospitality organizations. Investigation of the cultural intelligence as a moderator is one additional distinctive innovation and unique contribution of the present study. The hospitality industry is one of the most diverse industries in the world with a highly heterogeneous workforce and customers and cross-cultural interactions among them (Nazarian, Atkinson, \& Foroudi, 2017). This study is one of the first studies in hospitality research investigating how individuals' cultural ability and knowledge to adapt their interactions with people of other cultures affect the relationship between emotional intelligence and creative performance.

\section{THEORETICAL REVIEW}

\section{Emotional intelligence}

The primary concept of emotional intelligence (EI) refers to the individual's ability to consider one's own and others' emotions, discriminating between them and using this information to control one's own and others' thoughts and actions (Salovey \& Mayer, 1990). Goleman (1998) describes EI as a complex form of intelligence, comprising perceptual and cognitive abilities, and a main determinant of staff performance and positive organizational outcomes. Mayer et al. (1997) refined the definition of EI with the "four branch" model. This model consists of four abilities: the ability to understand their own and others' emotions; the ability to apply emotions for cognitive facilitation; the ability to perceive emotional information; and, finally, the ability to control their own and others' emotions. Another definition of EI, which is used to evaluate EI in the present study, is that by Wong et al. (2002), who argued that EI consists of four components: self-emotional evaluation, evaluation 
of others' emotions, adjustment of emotions, and using emotions. They also emphasized that EI is a significant predictor of work performance outcomes (e.g., creative performance and voluntary tasks). Since its introduction, the notion of emotional intelligence has emerged as a significant and effective antecedent of job-related attitudes, like organizational citizenship behavior (OCB), job satisfaction, safety behavior and deviant workplace behavior (Lu et al., 2016; Vratskikh et al., 2016). It also affects work related outcomes, such as innovation, service recovery performance, profitability and creativity (Kim et al., 2012; Prentice, 2016; Tsai \& Lee, 2014; Vratskikh et al., 2016). According to the above description, EI is a key factor for employees, especially frontline employees who are in direct contact with customers. These employees require this ability to manage their own and customers' emotions to present the best service delivery and effective service recovery.

\section{Cultural Intelligence}

Cultural intelligence (CI) can be described as an individual's ability to act effectively in culturally diverse environment (Ang \& Van Dyne, 2008). It refers to individuals' ability and skill to work in multicultural settings quickly, comfortably and effectively (Caligiuri, et al., 2011). Ang et al. (2008) consider four components for CI: cognitive, meta-cognitive, motivation, and behavior. Meta-cognitive CI refers to the capability of processing information during and after a culturally diverse experience. Cognitive CI focuses on the existing knowledge of norms, behaviors, and customs in different cultures. Motivational CI reflects the drive and willingness to seek out and participate in intercultural experiences and to be incentives to learn more about cultural diversities. Behavioral CI refers to the ability to participate in suitable verbal and nonverbal actions in intercultural settings. Cultural intelligence is unique in which it describes individuals' cultural ability and knowledge to adapt their interactions with people of other cultures. When the international tourist or guest interfaces directly with employees, it is the time that the customers' feelings, impressions and attitudes are formed about the organization (Bitner, Brown, \& Meuter, 2000). Since these customers come from different countries and cultures, it is critical for employees to show awareness of the different cultures and adapt themselves quickly based on the customer's culture to provide the optimum service (Shapero \& Collegium, 2006). MacNab's (2012) research on cultural intelligence shows that higher levels of CI permit individuals to perform in-the-moment modifications in a cross-cultural context. Furthermore, CI has been suggested as a key element of successful interactions in international markets (Alon \& Higgins, 2005), such as leadership effectiveness (Rockstuhl et al., 2011), cultural adaptation (Lee \& Sukoco, 2010), and innovation (Elenkov \& Manev, 2009).

\section{Environmental Uncertainty}

Environmental uncertainty (EU) is a complex, multidimensional phenomenon. It is described in the literature as a situation wherein upcoming events and changes are difficult to predict, a common challenge facing managers and entrepreneur directors (Thompson, 1967; Milliken, 1987; van Gelderen et al., 2006). For a long time, EU has been considered as a basic 
element of strategic management and entrepreneurship and also a significant determinant of organizations' market performance (Chen et al., 2005 ).

Decision makers perceive environmental uncertainty when there is a difference among available information and needed information (Milliken, 1987). Traditionally, managers try to prevent, eliminate and minimize EU via buffering or predicting fluctuations. However, in the age of modernization, EU presents itself as an opportunity for organizations to demonstrate creative performance and competitiveness.

There are at least three types of EU: state, effect and response uncertainty (Milliken, 1987). State uncertainty occurs when an employee is faced with a shortage of information and knowledge about the nature of the environment. Managers or employees experience this type of uncertainty when they understand the organizational environment, or part of its components, to be unforeseeable. The second type of uncertainty, effect uncertainty, refers to the lack of information on how environmental changes and events will impact on the organization and its outcomes. Response uncertainty is described as a lack of knowledge of response options and/or an inability to accurately anticipate the possible outcomes of response choices. It is experienced in the context of a need to make instant decisions (Milliken, 1987).

Bestieler (2005) believes that consumer markets and technology are two major sources of the rise of uncertainty. Market uncertainty refers to customer features and behavioral patterns and is described as instability or unpredictability of market prices, market economy, structure changes, new market regulations, and new products and services (Bestieler, 2005). Technological uncertainty refers to managers' inability to fully perceive or properly forecast different aspects of the technological environment. This kind of uncertainty becomes more prominent with increases in technological complexity and advancement (Song \& MontoyaWeiss, 2001).

High technology and market uncertainty compels organizations to be more flexible and adaptive to environmental changes. In confronting high market uncertainty, organizations are required to define and understand customers' demands proactively, so as to generate better competitive services and products (Jeong, Pae, \& Zhou, 2006). Environmental uncertainty varies from organization to organization along different phases of the organizational life cycle, and also varies based on the level of cognition of the significance of the external environment (Abeles, 2002). Employees perceive uncertainty in the workplace when they do not feel confident that they realize the crucial events or changes happening in the organization, or when they feel incapable of correctly assigning probabilities to the likelihood of special trends or events occurring (Milliken, 1987).

\section{Creative Performance}

Creativity has been described as the ability to produce novel ideas, novel behaviors, new concepts, new designs, new procedures of doing things, and updating old ideas to new and unique ones in performing job-related tasks (Wang \& Netemeyer, 2004). Creativity can be demonstrated in different ways in an organizational context, for instance, the presentation of unique ideas, new practical strategies, and new ways of working. Previous research has 
shown that creativity is defined by two aspects: first, novelty, which refers to new ideas and methods; second, quality, which refers to the development of suitable products and services (Amabile, 1996; Runco, 2014; Sternberg et al., 2012). While it has been demonstrated that creativity is a basic human feature dependent on stable characteristics (González, 2012), some research shows that it is the result of personal, cognitive, affective, behavioral, and contextual process (Amabile et al., 2005). One line of study on creativity is to discover its predictors. For instance, Andriopoulos (2001) highlights five items (organizational climate, culture, and structure, leadership style, resources and skills) to motivate employees' creativity in the workplace. Moreover, cultural diversity (Bouncken, Brem, \& Kraus, 2016), psychological empowerment, personality traits (Da Costa et al., 2015) and organizational climate (Jafri et al., 2016) have also been identified as sources of creativity. De Jong et al. (2007) assert that in order to achieve an ongoing flow of creativity, employees must show the desire and have the ability perform creatively. Sternberg (2012, p.5) proposes that "personality, intelligence, knowledge, thinking style, motivation, and environment" are factors associated with creativity. Da Costa et al. (2015), in their meta-analysis, show that individual factors such as intelligence, especially emotional intelligence, creative personality, divergent thinking, cognitive styles, self-efficacy, openness to experience and motivation, are important in creative performance. Researchers believe that creativity is vital for the long-term survival of organizations since it enables organizations to stay competitive in an uncertain and rapidly changing environment, and to gain competitive advantages (Beheshtifar \& Zare, 2013).

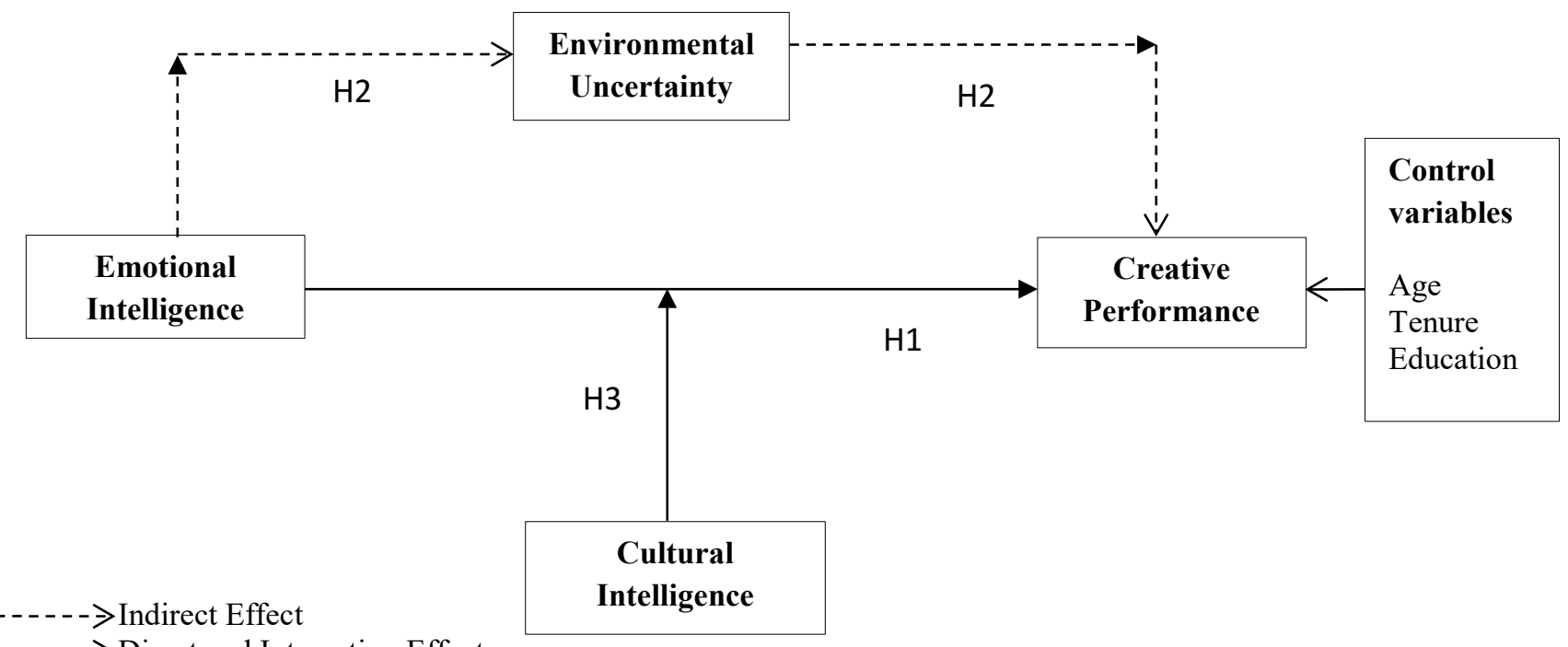

$\rightarrow$ Direct and Interaction Effect

\section{HYPOTHESES DEVELOPMENT}

\section{Emotional Intelligence and Creative Performance}

Study on the relevance of emotions at work has lately concentrated on the construct of emotional intelligence (EI). This construct may provide a feasible way of exploring how individuals' emotional abilities contribute to workplace outcomes (Chu et al., 2011). Related literatures show that the level of EI in individuals is related to job satisfaction (Wong \& Law, 2002), organizational citizenship behavior (Jung \& Yoon, 2012; Lee et al., 2011), customer satisfaction (Hochschild, 1983), emotional labor (Jung \& Yoon, 2014), job performance (George, 2000; Lopes et al., 2006), service performance (Chu et al., 2011) and individual and 
organizational success (Blanchard, 2010). Likewise, Kim et al. (2011) studied the relationship between employees' coping strategies and individual features such as emotional intelligence. EI is more related to voluntary behaviors beyond main roles (Kim et al., 2012; Wong et al., 2002).

EI can also be related to creativity and innovation. Emotional intelligence theory states that emotions make cognitive process adaptive and people can think rationally regarding emotions. Individuals have a wide range of intellectual abilities, and also measurable emotional skills which profoundly impact on their thinking and performance (Salovey \& Mayer, 1990). Emotional intelligence abilities enable individuals to handle their jobs which may involve high information processing such as knowledge work, and also use innovation and creativity in their work, such as produce new and useful ideas, obtain beneficial results (Parke, Seo, \& Sherf, 2015). Emotional intelligence, by enabling an individual to become aware of the relation between mood and performance, and maintaining positive moods, can thereby indirectly promote creative thinking (Ivcevic et al., 2007). Further studies show that EI plays an important role in employees' creativity (Barczak et al., 2010; Khalid et al., 2014; Tsai \& Lee, 2014). Barczak et al. (2010) show that team emotional intelligence enhances team trust in the workplace. Trust, in turn, promotes a corporate culture which increases creativity among team members and affects behavioral decision-making. The results of their study of 170 travel agencies' employees show that all four components of EI (self-emotional assessment, appraise others' emotion, emotion regulations, and use of emotions) are positively and significantly related to employee creativity (implementation of novel ideas or methods to enhance job productivity and thinking creatively for job or work tasks) (Tsai et al., 2014). Accordingly, the authors' study predicts that EI has a positive effect on CP among frontline employees (FEs) in the hospitality industry. Thus:

H1: Emotional intelligence positively affects FEs' creative performance.

\section{Environmental Uncertainty as a Mediator}

Besides examining the magnitude of the emotional intelligence-creative performance linkage, we are interested in exploring the causal mechanisms that might underpin the relationship. How can emotional intelligence lead to creative performance? How do emotionally intelligent employees show more creative performance? One possibility lies in the domain of environmental uncertainty. Environmental uncertainty denotes the unpredictability of environmental or organizational changes that affect organizational performance or the inadequacy of information about these variables. Therefore, it follows that uncertainty could lessen the predictability of corporate performance. We posit that emotionally intelligent employees have an ability to predict environmental uncertainty and show creative performance. Phrased alternatively, emotional intelligence can be perceived as one's capacity to achieve abstract thought and the ability to adapt to environmental changes (Cherniss, 2010).

Today, scientific evidence demonstrates that EI has a significant impact on individuals' cognitive processing, and that a balance between cognition and emotion could be the best and most important strategy for right environmental and social adjustment (see, 
among others, Barrett, 2013; Salovey \& Mayer, 1990). According to social cognitive theory (SCT), individuals' knowledge and ability can be directly related to observing others within the context of social interactions and experiences (Zimmerman \& Paulsen, 1995). Having and identifying the cognitive differences thanks to emotional intelligence, means that more efficient consequences could result in an uncertain environment (Domínguez, 2013). Calori et al. (1994) assert that emotionally intelligent employees of diversifiable organizations have this ability to predict environmental uncertainty and adapt themselves to environmental complexity which can result in creative performance. Moreover, Orme et al. (2002) argue that EI is a significant factor to meet environmental needs. EI, in fact, provides guideline for best decisions under conditions of uncertainty (Schwarz, 1990). Ameriks et al. (2009) believe that individuals with the ability to manage their EI tend to make better decisions, especially when faced with an uncertain condition in which a right decision is impossible. Lashgari (2015) mentions that investors via managing their emotions, could keep an acceptable level of performance. In the hospitality industry, which is characterized by environmental uncertainty (see, among others, Harrington, 2001; Jogaratnam \& Wong, 2009), emotionally intelligent employees may show creative performance by forming an emotional relationship with customers and thus overcome environmental uncertainty. Ezzi et al. (2016) show that emotionally intelligent leaders, through forecasting and adapting themselves to the environmental changes, are more capable of solving problems and effectively developing strategies for employees and customers. Psychological theories of judgement, choice and decision making developed in the late 1980s and early 1990s, reinforce the role of environmental uncertainty in influencing negatively creative performance. For example, Hogarth (1987) suggested that much of creativity involves cognitive abilities of generating alternative explanations or determining causes. Hogarth (1987) theorized four components of causal reasoning relevant to creativity: (i) a causal field which provides the environmental context in which judgments are made; (ii) contextual cues-to-causality (indicators of the existence of causal relations); (iii) EI-based judgmental strategies for combining the field and cues in the assessment of cause; (iv) alternative explanations. Hogarth (1987) observed that the order brought to bear on the information confronted by individuals (employees) through causal reasoning in uncertain environments is bought at the cost of being able to perceive alternative problem formulations. Sawyer (1990) found support for the hypothesis that the uncertainty in causal relations brought about through contextual ambiguity and low predictability will lead people to follow status quo strategies instead of creative solutions, even when the former strategies are suboptimal. These theories, therefore, provide a strong theoretical foundation for postulating both that: (a) environmental uncertainty, by reducing the capacity to perceive alternative problem formulations, affects negatively creative performance; (b) high EI - by virtue of its ability to increase the predictability of environmental uncertainty and hence attenuate its consequences - facilitates generating alternative explanations and determining causes, thereby enhancing creative performance. Thus we hypothesize that:

$\mathrm{H}$ 2: Emotional intelligence exerts an indirect positive effect on FEs' creative performance through reducing environmental uncertainty. 


\section{Cultural Intelligence as a Moderator}

There has been exponential growth in the need for hospitality services worldwide. Organizations, customers and employees have all become international and multicultural (Ljubica \& Dulcic, 2012). Therefore, the significance of effective cross-cultural management in the hospitality industry is being increasingly recognized as it enables the adequate promotion of hotel competitive services. The role of service providers like frontline employees, therefore, becomes very important when dealing with international customers. Based on social categorization theory (Tajfel \& Turner, 1986), categorizing process may decrease individual creativity in a culturally diverse environment. However, we believe that if a culturally diverse environment is properly managed, it can lead to an excellent performance outcome such as creativity. Cultural Intelligence (CI), as a multidimensional social-mental construct, provides an opportunity to explore, understand and interact with diverse cultures more effectively with respect to the organizational goals (Ljubica \& Dulcic, 2012).

Cultural intelligence is defined as an individual's ability to explore and attract different cultural motives and to act accordingly in multi-cultural conditions (Ang \& Van Dyne, 2008). Trifilova et al. (2012) note that $\mathrm{CI}$ is the ability to create a fruitful collaboration in situations where cultural differences play a role. CI can be a significant competence in innovation management through giving a framework for understanding different cultures, influencing ways of thinking, interpreting one another's contributions and acting in an unpredictable situation (Trifilova et al., 2012). Therefore, we expect that cultural intelligence can reduce potentially negative consequences of the social categorization process and, in turn, trigger creative performance among culturally diverse coworkers and customers.

Although there are some studies pertaining to the relationship between CI and performance (Jyoti et al., 2015; Sozbilir et al., 2016), few studies explore the relationship between CI and creativity (Joupari \& Far, 2015). A study was conducted by Altememi et al. (2015) on a sample of 258 employees in 5-star hotels in Jordan, which showed that cultural intelligence positively affects employees' creative capabilities. Further to this, Joupari and Far (2015) explored the relationship between the two variables and showed that CI is positively associated with employee creativity. Creativity is considered the result of the interaction between individuals' factors and environmental factors, with an emphasis on personality features (Batey \& Furnham, 2006). In the hospitality industry, which is characterized by an increasingly diverse cultural environment, employees encounter socio-cultural challenges. Employees' acceptance of the need to grow one's own emotional and cultural intelligence may increase the ability to deal with uncertain situations in a cross-cultural context. Both EI and $\mathrm{CI}$ include capabilities that facilitate effective interpersonal interactions. EI focuses on detecting and regulating one another's emotions while CI focuses more broadly on cognition, emotion and intentions of self and others, and explicitly on intercultural interactions. Both notions, EI and CI, are associated with social and personal intelligence and may have highly important applications in social and organizational environments. Importantly, research to date shows that $\mathrm{CI}$ is a key predictor of performance when the work context is culturally diverse (Rockstuhl et al., 2011). Culturally intelligent employees also possess the potential to drive up innovation and creativity, due to their ability to integrate diverse resources and help 
the business make best use of the multiple perspectives which multicultural customers bring to the organization. In addition to the direct impacts of EI and CI on creativity, there may be an interaction effect between both constructs in their impact on creativity. Lin et al. (2012) examine the interaction effect of EI and CI and individuals' adaptation in a different cultural setting. The results demonstrate the significance of CI and EI in realizing the links regarding cross-cultural adjustment. Since studies on personal abilities or resources to perform and control efficiently in culturally different environments have been spare and unsystematic, there is a significant gap in our understanding of why some employees are more creative than others and adapt better in an uncertainty situation. As underscored above, theory suggests that the multicultural competency embedded in CI, comprising of cultural knowledge and an extended repertoire of behavioural skills (Crowne, 2013) not only exerts a positive effect on EI and creativity, it can also be expected to augment the effect of EI on creative performance, thereby moderating the relationship by magnifying the effect. We mentioned that EI, by enabling an individual to become aware of the relation between mood and performance, and maintaining positive moods, can promote creative thinking. To the extent that the components of CI have been hypothesized to predict cultural judgement, decision-making, cultural adaptation, and task performance (Crowne, 2013; Ang et al., 2007), there is a theoretical rationale for postulating that CI can play a moderating role on the relationship between EI and creativity. Crowne (2013) specifically postulates that exposure to multicultural contexts and other cultures will lead to higher levels of both CI and EI. The reinforcing role of CI on the relationship between EI and creativity is also justified on the basis of research that posits that cultural adaptability enhances one's own and others' mood, emotion and personality, thereby accentuating EI and its capacity to affect actions and task performance, including creativity (Crowne, 2013; Yamazaki \& Kayes, 2004). With regard to the relationship between CI and EI, this paper, therefore, proposes that if employees have high levels of EI and CI simultaneously, they will exhibit more creativity. Accordingly, the study postulates the moderating role of $\mathrm{CI}$ on the EI-creative performance relationship.

H3: Cultural intelligence moderates the relationship between emotional intelligence and FEs' creative performance.

\section{METHOD}

\section{Sample and Data Collection}

The research was conducted in the hospitality industry in north Cyprus. A purposive sampling was used to obtain only four and five star hotels, which have appropriate characteristics in line with the goals of the research; in addition, these organizations can strongly emphasize employees' EI presentation in the workplace (Altememi et al., 2015; Kim et al., 2012). According to the ministry of tourism, there were 15 five-star and 4 four-star hotels in north Cyprus at the time of the survey (Darvishmotevali, Arasli, \& Kilic, 2017). The research team contacted all of these four and five star hotels' administrations prior to the execution of the research. Among these hotels, 9 five-star hotels and 2 four-star hotels participated in the research. Ultimately, the sample was selected based on judgmental 
sampling of frontline employees (FEs), specifically, door attendants, bell attendants, concierges, bartenders, receptionists, as well as food/beverage servers who are believed to have frequent contact with customers. This technique enables the researcher to select the respondents based on relevant criteria that are assumed to be representative of the population (Babakus, Yavas, \& Karatepe, 2017). To facilitate the data collection, the researchers approached the management of the selected hotels with a letter requesting authorization to distribute a self-report survey to employees. A senior staff member was assigned by management accompanied by one member of the research team to distribute the questionnaires among FEs. To avoid the risk of selection bias, questionnaires were distributed to employees holding various front-line service positions. A self-administered questionnaire together with an empty envelope was given to each of the employees, who were asked to deliver the completed questionnaire in the sealed envelope to reception before finishing work for the day. In addition, information given in the questionnaire reassured respondents about confidentiality and anonymity as well as there being no 'right' or 'wrong' answer for each item.

Out of the 350 questionnaires distributed to FEs, 289 questionnaires were returned, of which 283 were valid and used in the analysis (representing a response rate of $80.86 \%$ ). Demographic information indicated that $39 \%(n=110)$ of the respondents were between the ages of 30-35 while only $2.5 \%(n=7)$ were 41 and above years old. In terms of gender, $52 \%$ $(n=148)$ of respondents were female. Regarding tenure, $8 \%(n=31)$ had tenure for less than one year, $40 \%(n=114)$ had tenure for 1 to 5 years, and $36.7 \%(n=104)$ had tenure for 6 to 10 years. Regarding education level, $31 \%(n=89)$ completed a vocational program, and $46.6 \%$ $(n=132)$ had a bachelor's degree.

\section{Measurement}

Emotional intelligence was tested using sixteen items adopted from the scale of Law et al. (2004). Three items adopted from Sathe (1974) and Ferris (1982) were used to test environmental uncertainty. Cultural intelligence was measured using nine items based on the studies by Ang et al. (2008) and Konanahalli et al. (2014). Finally, six items obtained from Wang and Netmeyer (2004) were used to test creative performance. All items are listed in Table 2. In testing the hypotheses, the researches controlled for age, education level and tenure, which were found to be related to research variables. All four constructs were measured on a 5-point Likert scale ranging from $5=$ strongly agree to $1=$ strongly disagree. Frontline employees reported on dependent variables and demographic information, whereas supervisors rated creative performance to minimize the possibility of common method bias. All items were originally developed in English and thereafter translated into Turkish. Subsequently, all questions were translated back into English to check that the translated version (Turkish) was comparable to the original. A pilot study was conducted to measure face validity of the study measurement scales with 15 FEs and 2 supervisors. No changes were necessary based on the results.

\section{Data Analysis}


The data were analyzed using the statistical software packages LISREL 8.54 and SPSS 22. Confirmatory factor analysis (CFA) was used to assess construct validity (Joreskog \& Sorbom, 1996). Furthermore, Structural Equation Modeling (SEM) was conducted to assess whether the theoretical model fit to the available data. Hierarchical multiple regression was employed to test the mediating and moderating effects. In addition, the Sobel test was used to measure the significance of intermediary effect.

\section{RESULTS}

\section{Measurement Results and Descriptive Statistics}

The researchers conducted a series of CFAs using LISREL to examine the factorial validity of the measures via maximum likelihood estimation. We first defined a four-factor base model (M0), where (F1) emotional intelligence, (F2) environmental uncertainty, (F3) cultural intelligence, and (F4) creative performance were considered as separate factors. Next, the proposed model (M0) compared with several substitute models (M1, M2, and M3). The results in Table 1 showed that the four-factor model (M0) based on CFA ( $\chi 2=1334.55$, $\mathrm{df}=$ 521; $\chi 2 / \mathrm{df}=2.56$; comparative fit index $(\mathrm{CFI})=0.98$; incremental fit index (IFI) = .98; Goodness Fit Index $(\mathrm{GFI})=0.78$; Root Mean Square Error of Approximation (RMSEA) $=$ .07) had an acceptable fit to the data.

Table 1 Results of model comparisons using a CFA approach

\begin{tabular}{|c|c|c|c|c|c|c|c|c|c|}
\hline Models & Descriptions & $\chi^{2}$ & $d f$ & $\chi 2 / \mathrm{df}$ & CFI & GFI & IFI & RMR & RMSEA \\
\hline $\begin{array}{l}\text { Four-factor } \\
\text { Model (M0) }\end{array}$ & $\begin{array}{l}\text { F1: EI; F2: EU } \\
\text { F3: CI; F4: CP }\end{array}$ & 1334.55 & 521 & 2.56 & 0.98 & 0.78 & 0.98 & 0.04 & 0.07 \\
\hline $\begin{array}{l}\text { Three-factor } \\
\text { Model (M1) }\end{array}$ & $\begin{array}{l}\text { F1: EI\&EU } \\
\text { F2: CI; F3: CP }\end{array}$ & 2102.34 & 524 & 4.01 & 0.95 & 0.70 & 0.95 & 0.10 & 0.10 \\
\hline $\begin{array}{l}\text { Two-factor } \\
\text { Model (M2) }\end{array}$ & $\begin{array}{l}\text { F1: EI, EU\&CI } \\
\text { F2: CP }\end{array}$ & 2184.86 & 526 & 4.15 & 0.81 & 0.19 & 0.81 & 0.37 & 0.36 \\
\hline $\begin{array}{l}\text { One-factor } \\
\text { Model (M3) }\end{array}$ & $\begin{array}{l}\text { F1: EI, EU, } \\
\text { CI \&CP }\end{array}$ & 2427.33 & 527 & 4.61 & 0.77 & 0.17 & 0.77 & 0.39 & 0.40 \\
\hline
\end{tabular}

Table 2 Items, Factor Loadings and Construct Validity Results

\begin{tabular}{lccc} 
Items & $\begin{array}{c}\text { Standardized } \\
\text { Loadings }\end{array}$ & T-Value & \\
\hline Emotional Intelligence (law et al., 2004) & & \\
AVE & & .741 \\
Knowing others' emotions from their behaviors. & .838 & 17.371 & .979 \\
Good observer of others' emotions. & .837 & 17.362 \\
Sensitive to others' feelings and emotions & .855 & 17.934 \\
Understanding others' emotions & .871 & 18.471 \\
Setting goals for myself and then try to achieve them. & .857 & 18.004 \\
Telling myself that I am a competent person. & .866 & 17.986 \\
I am a self-motivated. & .925 & 20.459 \\
Encouraging myself to do my best. & .875 & 18.615
\end{tabular}


Knowing whether I am pleased or not.

Ability to control my temper and difficulties rationally.

Quite capability to control my own emotions.

calm down quickly when I am very nervous.

having good control of my own emotions.
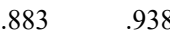

.105

.069

.940

How often you are sure regarding what the behaviors or expectations of the customers are that you have to try to meet as part of your work? How often you are sure regarding how to answer to the customers' behaviors or expectations?

How often you can determine whether your answer to meet

the customers action or expectation is effective?

Cultural Intelligence (Ang et al., 2008)

I am aware of the cultural knowledge when interacting

with individuals from different cultures

I adapt my cultural information when interacting with individuals

from unfamiliar culture.

I have information regarding legal and systems of customer' countries.

I know some of the customers language' rules (i.e. vocabulary,

grammar).

I know clients' cultural values and religious beliefs.

I am certain that I have this ability to deal with the stress of adapting with customers from different cultures.

I can change my verbal behavior (e.g. accent, tone) when interacting with customers from different cultures.

I can change my non-verbal behavior when interacting with

customers from different cultures.

20.583

20.868

Creative Performance (Wang et al., 2004)

Carrying out his/her routine tasks in resourceful ways.

coming up with novel ideas to satisfy customer needs.

Generating and evaluating multiple alternatives for

customer problems.

Having new perspectives on old difficulties.

Providing methods for solving problems when existing answers

are not apparent.

Generating creative ideas for service delivery.

In the next step, the construct validity of the measurement model was tested. Composite Reliability (CR) and Average Variance Extracted (AVE) were used to evaluate the convergent validity $(\mathrm{CR}>0.70$; $\mathrm{AVE}>0.50 ; \mathrm{CR}>\mathrm{AVE})$ while the Maximum Shared Squared Variance (MSV) and Average Squared Variance (ASV) were used to evaluate the discriminant validity (MSV $<$ AVE; ASV $<$ AVE) of the measurement model (Hair et al., 2010). Moreover, discriminant validity was also tested by comparing the square root of the AVE of each construct and its correlation coefficients with other constructs (Fornell \& Larcker, 1981). The results showed that AVE and CR for each latent variable were greater than 0.50 and 0.70 , respectively. MSV and ASV results were lower compared to the AVE values, also square roots of AVE for all four latent variables were greater than the correlation coefficients of other constructs, which provides evidence of convergent and discriminant validity among the measurements. Table 2 depicts Standardized loadings, AVE, CR, MSV, and ASV for all constructs.

A set of fit indices was used to test the structural model. The results showed that the hypothesized four-factor structural model, including EI, EU, CI, and CP fit the data well, $(\chi 2=$ 4.22, $\mathrm{df}=1 ; \chi 2 / \mathrm{df}=4.22 ; \mathrm{CFI}=0.99 ; \mathrm{GFI}=0.99 ; \mathrm{NFI}=0.98 ; \mathrm{IFI}=0.99 ;$ and $\mathrm{RMR}=0.03$,). 
The structural model tested the mediating role of environmental uncertainty, as well as the moderating effect of cultural intelligence on the relation between emotional intelligence and creative performance.

Composite scores for all measures were calculated by averaging scores of items related to each latent variable. Means, Standard Deviations (SD), Cronbach's alpha, and the correlations among research variables are presented in Table 3. EI correlated significantly with age $(\mathrm{r}=.14)$, tenure $(\mathrm{r}=11)$, education $(\mathrm{r}=18), \mathrm{EU}(\mathrm{r}=.17), \mathrm{CI}(\mathrm{r}=.20)$, and $\mathrm{CP}(\mathrm{r}=.43)$.

Table 3 Means, SD, C $\alpha$ and Correlations

\begin{tabular}{|c|c|c|c|c|c|c|c|c|c|c|c|}
\hline Variables & Mean & SD & $\mathrm{C} \alpha$ & 1 & 2 & 3 & 4 & 5 & 6 & 7 & 8 \\
\hline 1- Age & 2.50 & .92 & - & 1.00 & & & & & & & \\
\hline 2- Gender & .56 & .50 & - & -.02 & 1.00 & & & & & & \\
\hline 3- Tenure & 2.61 & .90 & - & $.78^{*}$ & -.02 & 1.00 & & & & & \\
\hline 4- Education level & 3.76 & .79 & - & .01 & -.02 & -.02 & 1.00 & & & & \\
\hline 5- Emotional Intelligence & 4.28 & .68 & .97 & $.14 * * *$ & .06 & $.11 * * * *$ & $.18 * *$ & 1.00 & & & \\
\hline 6- Env. Uncertainty & 4.07 & .81 & .96 & .02 & -.05 & .03 & -.02 & $.17 * *$ & 1.00 & & \\
\hline 7- Cultural intelligence & 4.05 & 1.12 & .99 & .09 & .05 & -.00 & .02 & $.20 * *$ & $.27 *$ & 1.00 & \\
\hline 8- Creative performance & 4.11 & .77 & .94 & $.15^{* * *}$ & .04 & $.14 * * *$ & $.13 * * *$ & $.43^{*}$ & $.31 *$ & $.30^{*}$ & 1.00 \\
\hline
\end{tabular}

Note: Composite scores for each variable were computed by averaging respective item scores. Note: ${ }^{*} \mathrm{P}<.001,{ }^{*} \mathrm{P}<.01, * * * \mathrm{P}<.05, * * * * \mathrm{P}<.10$ (2-tailed test).

\section{Hypothesis Test Results}

Study hypotheses were tested using a three-step hierarchical linear regression in SPSS 22. As shown in Table 4, a significant positive impact emerged between EI $(\beta=.41, p<.001)$ and $\mathrm{CP}$, supporting $\mathrm{H} 1$. The findings regarding the indirect effect of EI on CP via EU are summarized in Table 4. As mentioned before, $\mathrm{H} 2$ proposed EU as a mediator of the effect of EI on CP. In the analysis predicting EU, age, tenure and education were entered in step 1 and EI in step 2. For predicting CP, age, tenure and education were entered in step 1, EI in step 2 and EU in step 3. The results showed that when EU $(\beta=.24, p<.001)$ was entered in the analysis, the magnitudes of the effect of EI $(\beta=.37, p<.001)$ on $\mathrm{CP}$ decreased but remained significant. The result of the Sobel test also shows that EU significantly mediates the relation between EI and CP $(\mathrm{t}=2.43, \mathrm{p}<.05)$. So the findings show that EU partially mediates the effect of EI on CP, supporting $\mathrm{H} 2$.

The authors used multiple moderated regression analysis to test $\mathrm{H} 3$ which proposed that CI would moderate the relationship between EI and CP. To test H3, age, tenure and education were entered in step 1, EI and CI in step 2, and the interaction (EI*CI) in step 3. The results presented in Table 5 show the significant positive effect of $E I(\beta=.36, p<.001)$ 
and $\mathrm{CI}(\beta=.23, \mathrm{p}<.001)$, on creative performance. The analysis shows that the joint effects of $\mathrm{EI}^{*} \mathrm{CI}(\beta=.80, \mathrm{p}<.05)$ and on $\mathrm{CP}$ are significant, suggesting that $\mathrm{CI}$ increases the positive effect of EI on CP. Although, prima facie, the interaction effect adds only marginally to the explaining power of the model, as stated by Chin et al. (2003, p. 211): "Even a small interaction effect can be meaningful under extreme moderating conditions, if the resulting beta changes are meaningful, then it is important to take these conditions into account." In addition, the researchers plotted the $\mathrm{EI}^{*} \mathrm{CI}$ interaction at two levels of $\mathrm{CI}$ (e.g., $+1 \mathrm{SD},-1 \mathrm{SD}$; Bauer et al., 2005) and conducted a simple slope test to examine the nature of the interaction. The interactions are graphically displayed in Fig. (2). Results show that CI strengthens the positive effect of EI on creative performance, therefore, $\mathrm{H} 3$ is accepted.

TABLE 4 Regression Results: direct and indirect effects

\begin{tabular}{|c|c|c|c|c|c|c|c|c|c|c|}
\hline \multirow[b]{2}{*}{ Variables } & \multicolumn{5}{|c|}{ Environmental Uncertainty } & \multicolumn{5}{|c|}{ Creative Performance } \\
\hline & $\beta$ & $t$ & $\beta$ & $t$ & $\beta$ & $t$ & $\beta$ & $t$ & $\beta$ & $t$ \\
\hline \multicolumn{11}{|l|}{ Step 1} \\
\hline Age & -.01 & -.05 & -.03 & -.27 & .08 & .88 & .03 & .37 & .04 & .46 \\
\hline Tenure & .04 & .38 & .03 & .34 & .08 & .89 & .07 & .86 & .07 & .80 \\
\hline Education & .03 & .43 & -.01 & -.07 & $.13 * * *$ & 2.28 & .06 & 1.08 & .06 & 1.14 \\
\hline \multicolumn{11}{|l|}{ Step2 } \\
\hline Emotional & ence & & $.17 * *$ & 2.75 & & & $.41^{*}$ & 7.45 & $.37 *$ & 6.86 \\
\hline \multicolumn{11}{|l|}{ Step 3} \\
\hline Environme & certai & & & & & & & & $.24 *$ & 4.62 \\
\hline$F$ & & .16 & & 2.01 & & $4.06 * *$ & & $17.52 *$ & & $19.32 *$ \\
\hline$R^{2}$ at each & & .00 & & .03 & & .04 & & .20 & & .26 \\
\hline$\triangle R^{2}$ & & & & .03 & & & & .16 & & .06 \\
\hline
\end{tabular}

Sobel Test:

Emotional Intelligence $\rightarrow$ Environmental Uncertainty $\rightarrow$ Creative performance: $2.23 * * *$

Note: $* \mathrm{P}<.001,{ }^{*} \mathrm{P}<.01,{ }^{* * *} \mathrm{P}<.05$ (2-tailed test). The result of variance inflation factor (VIF) did not show any problem of multicollinearity.

TABLE 5 Regression Results: Moderating Effects

Creative Performance

\begin{tabular}{lrrrrrr} 
& & & & & \\
Variables & $\beta$ & $t$ & $\beta$ & $t$ & & \\
\cline { 2 - 7 } & & & & & & \\
Step1 & & & & & & \\
Age & .08 & .88 & -.02 & -.19 & -.02 & -.24 \\
Tenure & .08 & .89 & .12 & 1.40 & .12 & 1.50 \\
Education & $.13^{* * *}$ & 2.28 & .07 & 1.38 & .06 & 1.20
\end{tabular}


Step2

Emotional Intelligence

Cultural Intelligence

$\begin{array}{llrr}.36^{*} & 6.67 & .01 & .08 \\ .23 * & 4.35 & -.41 & -1.32\end{array}$

Step 3

$\mathrm{EI} * \mathrm{CI}$

$.80 * * *$

F

$R^{2}$ at each step

$\triangle R^{2}$

$4.06 * *$

$18.71 *$

.25

$16.54 *$

.04

.21

.26

.01

Note: $* \mathrm{P}<.001,{ }^{*} \mathrm{P}<.01,{ }^{* * *} \mathrm{P}<.05$ (2-tailed test). The result of variance inflation factor (VIF) did not show any problem of multicollinearity.

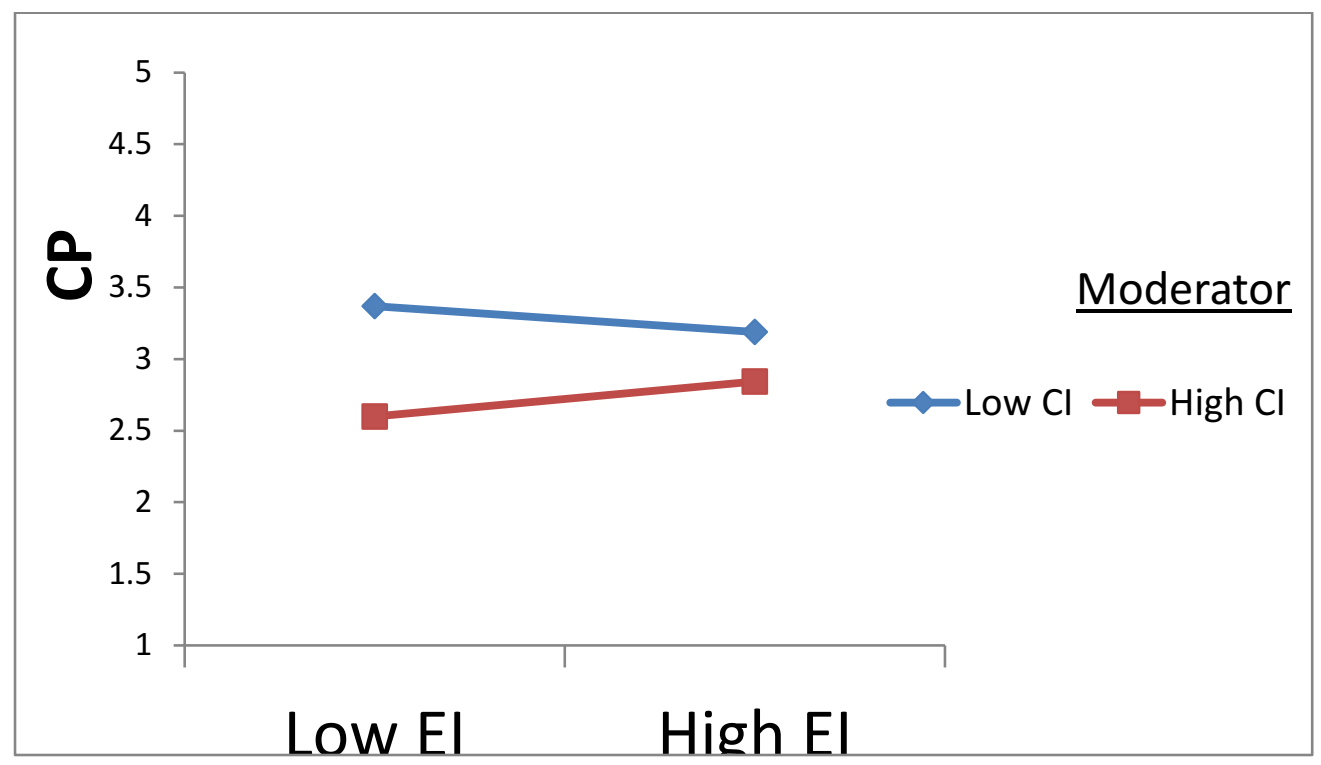

Fig 2. Interactive Effect of Emotional Intelligence and Cultural Intelligence

\section{DISCUSSION}

Over the past few decades, organizations in the hospitality industry have faced increased competition, which has arisen as a result of economic, social and cultural changes, political instability, fluctuations in the markets, changes in customer needs and technological innovations. Dealing with such challenges requires searching for strategies to raise standards, improve productivity, increase adaptability, gain flexibility, and become more agile and creative. Creativity is the company's pro-active response to an uncertain environment (Radu $\&$ Vasile, 2007). Frontline employees (FEs) form an integral part of the service industry and play a significant role in maintaining long-term relationships between organizations and customers (Kusluvan, 2003); they should not be ignored in creative performance debates. While relevant studies highlight a number of personal features which affect employees' creativity (Jiang et al., 2015; Carmeli et al., 2014; Vratskikh et al., 2016), the predictors of 
creative performance (CP) among FEs still remain to be studied in depth. This study has examined the impact of emotional intelligence (EI), as one of these important personal resources, on FEs' creative performance.

Support for H1 suggests that EI significantly and positively predicts $\mathrm{CP}$. The results show that high EI is strongly linked to $\mathrm{CP}$, which reveals the importance of employees' EI in their creative performance. Consistent with EI theory, individuals' differences in emotional intelligence influence each stage of the emotional experience, which ultimately influences creativity (Parke, Seo, \& Sherf, 2015). The theory also argues that emotions serve significant social functions, transforming information regarding other individuals' thoughts, intents, manners and behaviors (Keltner \& Haidt, 2001). Actually, the ability to combine emotional information into cognitive activities is necessary for an effective and creative functioning in interaction with others (Brackett, Rivers, \& Salovey, 2011). These findings also agree with the results of related previous studies (Jafri et al., 2016; Vratskikh et al., 2016; Da Costa et al., 2015), confirming that knowing and using emotions plays a role in both thinking and information processing (Mayer \& Salovey, 1997). Emotionally intelligent employees are better able to understand and manage their emotions and affect others' emotions, which enable them to understand the causes of conflict encountered with customers and develop conflict resolution strategies to foster positive interactions and performance in service recovery (Kim et al., 2012). In summary, high EI ability has the potential to contribute to employees' creative performance through facilitating employees' cognitive activities such as reasoning, decision-making and problem-solving (Jafri et al., 2016).

A number of studies (e.g., Khalid et al., 2014; Kim et al., 2012; Prentice, 2016) have previously focused on different variables and conditions as mediators of the impact of EI on $\mathrm{CP}$, but to the authors' knowledge there is no study focusing on environmental uncertainty (EU) as a mediator of this relationship. Regarding the mechanism through which EI affects $\mathrm{CP}$, the results show that emotionally intelligent employees are more creative in their performance through predicting environmental uncertainty. The results confirm the partially (directly and indirectly) mediating role of EU in the relationship between EI and CP, where EI affects creative performance via predicting EU. Our findings are consistent with hypotheses grounded on psychological theories of judgement, choice and decision making developed by Hogarth (1987) and Sawyer (1990), from which it can be inferred that environmental uncertainty can influence negatively creative performance. Moreover, in line with social cognitive theory and findings of previous studies (Ameriks et al., 2009; Ezzi et al., 2016), these results show that emotionally intelligent employees are more likely to be able to predict environmental uncertainty, adapt to environmental changes, solve problems and show creative performance in dealing with colleagues and customers.

The results of the multilevel analysis provide support for our argument based on social categorization theory (Turner et al., 1987), that cultural intelligence can reduce the social categorization process, and is, in turn, positively related to organizational creativity. Moreover, with regards to the moderating role of CI on the EI-CP relationship, it was found that CI strengthens the positive effect of EI on CP. Although there is no study to date which focuses on CI as a moderator in particular, this result supports Crowne (2013) and Ang et al. (2007) hypotheses that CI positively affects cultural adaptation and performance (Crowne, 
2013; Ang et al., 2007). The result also coincides with related previous findings (Côté, 2014; Jafri et al., 2016), which support the moderating role of personal resources in the mentioned relationship. Our results prove that the impact of emotional intelligence on creative performance depends on the levels of employees' cultural intelligence. As previously stated, employees with high levels of cultural intelligence have the ability to adapt quickly based on the customer's culture, and explore new ideas and actions to satisfy customers in the best way possible. Therefore, having emotional intelligence, which focuses on detection and regulation of one another's emotions, and also cultural intelligence, which focuses both on cognition and emotion of self and others and intercultural interaction simultaneously, results in more novel ideas and creative performance.

\section{CONCLUSION}

This research was conducted to achieve three objectives: (a) to evaluate the relationship between emotional intelligence (EI) and employees' creative performance (CP); (b) to examine the mediating role of environmental uncertainty (EU); and (c) to evaluate the moderating role of cultural intelligence $(\mathrm{CI})$ in the relation between EI and $\mathrm{CP}$ among frontline employees (FEs) in the hospitality industry. The analyses carried out provide evidence about the factors and mechanisms which augment employees' creative performance.

From a theoretical perspective, this research makes important and meaningful contributions to the existing literature in hospitality and service management. To date, very few empirical studies have been conducted on creative performance, its predictors, mechanisms, and interactive effect in the hospitality industry. Addressing this gap, this study tested emotional intelligence as a predictor of creative performance, the mediating role of environmental uncertainty and the moderating role of cultural intelligence among FEs in the hospitality industry.

The results of this study contribute to the recognition of the importance of EI in frontline employees' performance in general and creative performance in particular. More importantly, it is crucial to test the role of EU in the EI-CP relationship. Although a number of researchers have tested the mediating variables on the relationship between EI and CP (Khalid et al., 2014; Kim et al., 2012) none of them explored the mechanisms through which EI leads to $\mathrm{CP}$ in an uncertain environment. Consistent with social cognitive theory, high levels of EI enable employees to determine how to cope with and adapt to the uncertain environment, to be open, more agile, and more embracing of new performance imperatives from both the market place and within the organization. Accordingly, this study shows that FEs have the ability to predict EU and be creative in their performance in unstable situations.

Another theoretical contribution of this study concerns the moderating role of cultural intelligence. The authors' research advances on existing literature on creative performance by examining the interaction effect of EI with CI on creative performance. The proposed research model shows that FEs with simultaneously high levels of emotional intelligence and cultural intelligence, have a stronger ability to adapt quickly in uncertainty environments, explore novel ideas and show creative performance. 
From a practical point of view, the study makes important and valuable contributions in the field of hospitality and service management. Employees' creativity and innovation is one of the primary concerns of modern organizations; this applies especially to the hospitality industry, because of the direct link between employee creativity and organizational performance. In accordance with the results of our study, CP is indeed affected by EI, both directly and indirectly, via predicting EU. In this dynamic and demanding environment, introducing and augmenting high EI is a vital necessity as it is a significant predictor of creativity, and is essential to effectively manage the challenges in the workplace. High emotional intelligence reinforces communication skills, helping employees to think more creatively about how best to leverage their cognitive abilities. Managers should be aware that building the most productive and creative business requires an understanding of employees' skills, behaviors and motivations. As the worldwide economy has developed into a system featured by cooperation, negotiation, and communication, EI has grown to play an important role in the public domain. EI is correlated with traits such as self-regulation, self- awareness, and the ability to act under pressure. It provides employees, irrespective of their skills, with the emotional and social talent to adjust to environmental uncertainty. In addition, $\mathrm{CP}$ is increased in an interactive situation of EI and CI. Da Costa et al. (2015) emphasize that for innovation in the workplace emotional aspects such as emotional intelligence and cognitive facets like cultural intelligence are more important than motivational factors. Accordingly, it can be proposed that human resource managers take EI and CI into consideration in screening, hiring and capacity building activity aimed at improving performance outcomes in the workplace. So, selecting employees with high EI and CI would benefit innovation and creativity in the workplace. Moreover, organizations adopting practices, regulations and norms which reinforce a positive climate and positive emotions among the employees could have the same result.

EI and CI or other personal factors of creativity could be strengthened through training from the organization. This training could be accessed through different workshops or providing resources to employees for the purpose of developing their personal factors of creativity such as EI and CI. This could support and encourage employees to identify and perceive these two important factors of creativity and consider how to implement them in the workplace when dealing with co-workers or customers. In addition, organizations could pay greater attention to the conditions of human interactions, and practice to manage contrast between different emotions and cultures in the workplace.

\section{Limitations and Future Study}

Notwithstanding the significance of the findings, some final caveats are in order. In this work, we focused only on one predictor of creative performance. The recommendation for prospective future researchers is to consider other potential factors which can boost creative performance, such as other personality factors or organizational situations. Additionally, the authors recommend examination of other kinds of work outcomes or attitudes as a result of emotional intelligence's role in the hospitality industry. It is also suggested that further study should examine more variables with the potential to strengthen the EI-CP relationship. 
Moreover, the use of other statistical software packages to analyze this model, is highly recommended. Our data were collected at one point in time; therefore, future studies should consider collecting the data longitudinally. Since the data were collected in 4 and 5 star hotels in north Cyprus, there may also be limited generalizability of the findings, so future studies should focus on other sectors and explore other country contexts.

\section{REFERENCES}

Abeles, T. (2002). "From Certainty to Uncertainty", On the Horizon. 10( 2) 25 - 26.

Alon, I., \& Higgins, J. M. (2005). Global leadership success through emotional and cultural intelligences. Business horizons, 48(6), 501-512.

Altememi, A. F., Hassouneh, I. A., \& Alkshali, S. J. (2015). The Relationship between Creative Capabilities and Cultural Intelligence: Field Study of Amman's Five-Star Hotels. . International Journal of Business and Management, 10(12), 103-115.

Amabile, T. M. (1996). Creativity in context: Update to" the social psychology of creativity.". Boulder, CO: Westview press.

Amabile, T. M., Barsade, S. G., Mueller, J. S., \& Staw, B. M. (2005). Affect and creativity at work. Administrative science quarterly, 50(3), 367-403.

Ameriks, J., Wranik, T., \& Salovey, P. (2009). Emotional Intelligence and Investor Behavior. Charlottesville, VA: The Research Foundation of CFA Institute.

Andriopoulos, C. (2001). Determinants of organisational creativity: a literature review. Management decision, 39(10), 834-841.

Ang, S., \& Van Dyne, L. (2008). "Handbook of Cultural Intelligence: Theory, Measurement, and Applications”,(M. E. Sharpe; Armonk, NY).

Ang, S., Van Dyne, L., Koh, C., Ng, K. Y., Templer, K. J., Tay, C., et al. (2007). Cultural intelligence: Its measurement and effects on cultural judgment and decision making, cultural adaptation and task performance . Management and organization review, 3(3), 335-371.

Babakus, E., Yavas, U., \& Karatepe, O. (2017). "Work engagement and turnover intentions: Correlates and customer orientation as a moderator". International Journal of Contemporary Hospitality Management, 29 (6), 1580-1598.

Barczak, G., Lassk, F., \& Mulki, J. (2010). Antecedents of team creativity: An examination of team emotional intelligence, team trust and collaborative culture. Creativity and Innovation Management, 19(4), 332-345.

Barrett, L. F. (2013). Psychological construction: the darwinian approach to the science of emotion. Emotion Review, 5(4), 379-389. 
Batey, M., \& Furnham, A. (2006). Creativity, intelligence, and personality: A critical review of the scattered literature. . Genetic, Social, and General Psychology Monographs, $132(4), 355-429$.

Bauer, D., \& Curran, P. (2005). Probing interactions in fixed and multilevel regression: inferential and graphical techniques. Multivariate Behavioral Research, 40 (9), 18661886.

Beheshtifar, M., \& Zare, E. (2013). Employee Creativity: A compulsory Factor in Organizations. Interdisciplinary journal of contemporary research in business , 5(2), 242-247.

Bestieler, L. (2005). The moderating effect of environmental uncertainty on new product development and time efficiency. Journal of Product Innovation Management, 22(3), 267-284.

Bitner, M. J., Brown, S. W., \& Meuter, M. L. (2000). "Technology Infusion in Service Encounters.”. Journal of the Academy of Marketing Services, 28, (1), 138 - 149.

Blanchard, K. H. (2010). Leading at a higher level: Blanchard on leadership and creating high performing organizations. New Jersey: FT Press.

Bouncken, R., Brem, A., \& Kraus, S. (2016). Multi-cultural teams as sources for creativity and innovation: The role of cultural diversity on team performance. International Journal of Innovation Management, 20(01), 1-34.

Brackett, M. A., Rivers, E., \& Salovey, P. (2011). "Emotional intelligence: Implications for personal, social, academic, and workplace success." . Social and Personality Psychology Compass , 5 (1) : 88-103.

Caligiuri, P., Noe, R., Nolan, R., Ryan, A., \& Drasgow, F. (2011). Training, Developing, and Assessing Cross-Cultural Competence in Military Personnel. Arlington, Virginia: United States Army Research Institute for the Behavioral and Social Sciences.

Calori, R., Johnson, G., \& Sarnin, P. (1994). CEOs' cognitive maps and the scope of the organization. Strategic Management Journal, 15 (6), 437-457.

Carmeli, A., McKay, A. S., \& Kaufman, J. C. (2014). Emotional intelligence and creativity: The mediating role of generosity and vigor. The Journal of Creative Behavior, 48(4), 290-309.

Chang, J., \& Teng, C. (2017). Intrinsic or extrinsic motivations for hospitality employees' creativity: The moderating role of organization-level regulatory focus. International Journal of Hospitality Management, 60,133-141.

Chen, J., Reilly, R. R., \& Lynn, G. S. (2005). The impacts of speed-to-market on new product success: the moderating effects of uncertainty. IEEE Transactions on engineering management, 52(2), 199-212. 
Cherniss, C. (2010). Emotional intelligence: Toward clarification of a concept. Industrialand Organizational Psychology, 3(2), 110-126.

Chin, W. W., Marcolin, B. L., \& Newsted, P. R. (2003). A partial least squares latent variable modeling approach for measuring interaction effects: Results from a Monte Carlo simulation study and an electronic-mail emotion/adoption study. Information Systems Research, 14, 189-217.

Chu, K. H., Baker, M. A., \& Murrmann, S. K. (2011). When we are onstage, we smile: The effects of emotional labor on employee work outcomes. International Journal of Hospitality Management, 31, 906-915.

Coelho, F., Augusto, M., \& Lages, L. (2011). Contextual factors and the creativity of frontline employees: The mediating effect of role stress and intrinsic motivation. Journal of Retailing, 87(1), 31-45.

Côté, S. (2014). Emotional intelligence in organizations . Annu. Rev. Organ. Psychol. Organ. Behav., 1(1), 459-488.

Crowne, K. A. (2013). Cultural exposure, emotional intelligence, and cultural intelligence: An exploratory study. International Journal of Cross Cultural Management, 13(1), 5-22.

Da Costa, S., Páez, D., Sánchez, F., Garaigordobil, M., \& Gondim, S. (2015). Personal factors of creativity: A second order meta-analysis. Revista de Psicología del Trabajo y de las Organizaciones, 31(3), 165-173.

Darvishmotevali, M., Arasli, H., \& Kilic, H. (2017). Effect of job insecurity on frontline employee's performance: looking through the lens of psychological strains and leverages . International Journal of Contemporary Hospitality Management, 29(6), 1724-1744.

De Jong, J. P., \& Den Hartog, D. N. (2007). How leaders influence employees' innovative behaviour. European Journal of innovation management, 10(1), 41-64.

Domínguez, E. S. (2013). Work stressors and creativity.M@n@gement, 16(4),479-503.

Elenkov, D. S., \& Manev, I. M. (2009). Senior expatriate leadership's effects on innovation and the role of cultural intelligence. Journal of World Business, 44(4), 357-369.

Ezzi, F., Azouzi, M. A., \& Jarboui, A. (2016). Does CEO emotional intelligence affect the performance of the diversifiable companies? Cogent Economics \& Finance, 4(1), 1 17.

Feng, J., Zhang, Y., Liu, X., Zhang, L., \& Han, X. (2016). Just the Right Amount of Ethics Inspires Creativity: A Cross-Level Investigation of Ethical Leadership, Intrinsic Motivation, and Employee Creativity. Journal of Business Ethics, 1-14. 
Ferris, K. R. (1982). Perceived Environmental Uncertainty, Organizational Adaptation, and Employee Performance: A Longitudinal Study in Professional Accounting Firms. Accounting, Organizations and Society, 7(1) 13-26.

Fornell, C., \& Larcker, D. F. (1981). Evaluating structural equation models with unobservable variables and measurement error. Journal of marketing research, 18(1), 39-50.

George, J. M. (2000). Emotions and leadership: The role of emotional intelligence. Human Relations, 53(8), 1027-1055.

Goleman, D. (1998). Working with emotional intelligence. New York: Bantam.

González, A. (2012). PIC-A: Prueba de imaginación creativa para adultos. Madrid: Manual.

Hair, J., Black, W., Babin, B., \& Anderson, R. (2010). multivariate data analysis (7th ed.). New Jersey: Prentice Hall.

Harrington, R. (2001). Environmental Uncertainty within the Hospitality Industry: Exploring the Measure of Dynamism and Complexity between Restaurant Segments. International Journal of Hospitality \& Tourism Administration , 25(4), 386-398.

Harrington, R. (2001). Environmental Uncertainty within the Hospitality Industry: Exploring the Measure of Dynamism and Complexity between Restaurant Segments. International Journal of Hospitality \& Tourism Administration, 25(4), 386-398.

Hochschild, A. (1983). The managed heart: Commercialization of human feeling. Berkeley: University of California Press. .

Hogarth, R. M. (1987). Judgment and choice: The psychology of decision . New York: Wiley.

Ivcevic, Z., Brackett, M. A., \& Mayer, J. D. (2007). Emotional intelligence and emotional creativity. Journal of Personality, 75(2), 199-236.

Jafri, M. H., Dem, C., \& Choden, S. (2016). Emotional Intelligence and Employee Creativity: Moderating Role of Proactive Personality and Organizational Climate. Business Perspectives and Research, 4(1), 54-66.

Jeong, I., Pae, J. H., \& Zhou, D. (2006). Antecedents and consequences of the strategic orientations in new product development: The case of Chinese manufacturers . Industrial Marketing Management, 35(3), 348-358.

Jiang, W., \& Gu, Q. (2015). A moderated mediation examination of proactive personality on employee creativity: A person-environment fit perspective. Journal of Organizational Change Management, 28(3), 393-410.

Jogaratnam, G., \& Wong, K. (2009). Environmental Uncertainty and Scanning Behavior: An Assessment of Top-Level Hotel Executives . International Journal of Hospitality \& Tourism Administration, 10 (1), 44-67. 
Joreskog, K., \& Sorbom, D. (1996). LISREL 8: User's Reference Guide. Chicago: Scientific Software International, Inc.

Joseph, D. L., \& Newman, D. A. (2010). Emotional intelligence: An integrative meta-analysis and cascading model. Journal of Applied Psychology, 95(1), 54-78.

Joupari, N. Z., \& Far, M. B. (2015). Investigating the Relationship between Social Capital and Cultural Intelligence with Organizational Innovation in the Supreme Audit Court. Jurnal UMP Social Sciences and Technology Management, 3(2),409-420.

Jung, H. S., \& Yoon, H. H. (2014). Moderating role of hotel employees' gender and job position on the relationship between emotional intelligence and emotional labor. . International Journal of Hospitality Management, 43, 47-52.

Jung, H., \& Yoon, H. (2012). The effects of emotional intelligence on counterproductive work behaviors and organizational citizen behaviors among food and beverage employees in a deluxe hotel. International Journal of Hospitality Management, 31(2),369- 378.

Jyoti, J., Kour, S., \& Bhau, S. (2015). Assessing the Impact of Cultural Intelligence on Job Performance: Role of Cross-Cultural Adaptability. Journal of IMS Group, 12(1), 2333.

Kattara, H., \& El-Said, O. (2014). Innovation strategies: The implementation of creativity principles in Egyptian hotels. Tourism and Hospitality Research, 13(3), 140-148.

Keltner, D., \& Haidt, J. (2001). Social functions of emotions. In T. J. Mayne \& G. A. Bonanno (Eds.), Emotions: Current Issues and Future Directions (pp. 192-213). New York: Guilford Press.

Khalid, S., \& Zubair, A. (2014). Emotional intelligence, self-efficacy, and creativity among employees of advertising agencies. Pakistan Journal of Psychological Research, 29(2), 203-221.

Kim, H. J., \& Agrusa, J. (2011). Hospitality service employees' coping styles: The role of emotional intelligence, two basic personality traits, and socio-demographic factors. International Journal of Hospitality Management, 30(3), 588-598.

Kim, T., Yoo, J., Lee, G., \& Kim, J. (2012). Emotional intelligence and emotional labor acting strategies among frontline hotel employees. international journal of contemporary hospitality managemnet, 24 (7), 1029-1046.

Konanahalli, A. O., Oyedele, L., Spillane, J., Coates, R., von Meding, J., \& Ebohon, J. (2014). Cross-cultural intelligence (CQ) It's impact on British expatriate adjustment on international construction projects. International Journal of Managing Projects in Business, 7(3), 423-448.

Kusluvan, S. (2003). Managing employee attitudes and behaviors in the tourism and hospitality industry. New York: Nova Publishers. 
Lashgari, M. (2015). Decision Making under Uncertainty the Impacts of Emotional Intelligence and Behavioral Patterns. Academy of Accounting and Financial Studies Journal, 19(2), 159-166.

Law, K. S., Wong, C.-S., \& Song, L. J. (2004). The construct and criterion validity of emotional intelligence and its potential utility for management studies . Journal of Applied Psychology, 89(3), 483-496.

Lee, G., Magnini, V. P., \& Kim, B. P. (2011). Employee satisfaction with schedule flexibility: Psychological antecedents and consequences within the workplace. International Journal of Hospitality Management, 30(1), 22-30.

Lee, L. Y., \& Sukoco, B. M. (2010). The effects of cultural intelligence on expatriate performance: The moderating effects of international experience. The International Journal of Human Resource Management, 21(7), 963-981.

Lin, Y. C., Chen, A. S., \& Song, Y. C. (2012). Does your intelligence help to survive in a foreign jungle? The effects of cultural intelligence and emotional intelligence on crosscultural adjustment. International Journal of Intercultural Relations, 36(4), 541-552.

Ljubica, J., \& Dulcic, Z. (2012). The Role Of Cultural Intelligence (Cq) In The Strategy Formulation Process - Application To The Hotel Industry. 23rd International DAAAM Symposium (pp. 0115-0120). Vienna: International DAAAM.

Lopes, P. N., Grewal, D., Kadis, J., Gall, M., \& Salovey, P. (2006). "Evidence that emotional intelligence is related to job performance and affect and attitudes at work". Psicothema, 18, suppl. pp. 132-138.

MacNab, B. R. (2012). An experiential approach to cultural intelligence education. Journal of Management Education, 36(1), 66-94.

Mayer, J. D., \& Salovey, P. (1997). What is emotional intelligence? In P. Salovey \& D. Sluyter (Eds). Emotional development and emotional intelligence: Implications for educators (pp. 3-31). New York: Basic Books.

Miller, K. D. (1992). A framework for integrated risk management in international business . Journal of international business studies, 23(2), 311-331.

Milliken, F. (1987). Three types of perceived uncertainty about the environment: State, effect, and response uncertainty. Academy of management review, 12(1), 133-143.

Mittal, S., \& Dhar, R. L. (2015). Transformational leadership and employee creativity: mediating role of creative self-efficacy and moderating role of knowledge sharing. Management Decision, 53(5), 894-910.

Nazarian, A., Atkinson, P., \& Foroudi, P. (2017). Influence of national culture and balanced organizational culture on the hotel industry's performance. International Journal of Hospitality Management, 63, 22-32. 
Orme, G., \& Bar-On, R. (2002). The contribution of emotional intelligence to individual and organisational effectiveness. Competency and Emotional Intelligence, 9 (4), 23-28.

Parke, M. R., Seo, M.-G., \& Sherf, E. N. (2015). Regulating and facilitating: The role of emotional intelligence in maintaining and using positive affect for creativity. Journal of Applied Psychology, 100(3), 917-934.

Prentice, C. (2016). Leveraging employee emotional intelligence in casino profitability. journal employee emotional intelligence in casino profitability, 33,127-134.

Prentice, C., \& King, B. E. (2013). Impacts of personality, emotional intelligence and adaptiveness on service performance of casino hosts: A hierarchical approach. Journal of business research, 66(9), 1637-1643.

Radu, E., \& Vasile, D. C. (2007). Innovation in the hospitality industry. . The Journal of the Faculty of Economics-Economic Science Series, 1, 239-42.

Rockstuhl, T., Seiler, S., Ang, S., Van Dyne, L., \& Annen, H. (2011). Beyond General Intelligence (IQ) and Emotional Intelligence (EQ): The Role of Cultural Intelligence (CQ) on Cross-Border Leadership Effectiveness in a Globalized World. Journal of Social Issues, 67(4), 825-840.

Runco, M. A. (2014). Creativity: Theories and themes: Research, development, and practice. Amsterdam: Elsevier.

Salovey, P., \& Mayer, J. D. (1990). Emotional intelligence. Imagination, Cognition and Personality,. Baywood publishing co., Ine, 9(3), 185-211.

Sathe, V. V. (1974). Structural Adaptation to Environment: Study of Insurance Company Departments and Branch Banks. Unpublished Ph.D. Dissertation, Ohio State University.

Sawyer, J. E. (1990). Effects of risk and ambiguity on judgments of contingency relations and behavioral resource allocation decisions. Organizational Behavior and Human Decision Processes, 45, 85-110.

Schwarz, N. (1990). Feelings as information: informational and motivational functions of affective states. New York: Guilford Press.

Shapero, M. A., \& Collegium, C. C. (2006). Cross cultural training for hospitality and tourism: improving service encounters through industry targeted critical incidents. Comparative Cultures Collegium. Eckerd College.

Sigala, M., \& Chalkiti, K. (2015). Knowledge management, social media and employee creativity. International Journal of Hospitality Management, 45, 44-58.

Song, M., \& Montoya-Weiss, M. M. (2001). The effect of perceived technological uncertainty on Japanese new product development. Academy of Management journal , 44(1), 6180 . 
Sozbilir, F., \& Yesil, S. (2016). The impact of Cultural Intelligence (CQ) on Cross-Cultural Job Satisfaction (CCJS) and International Related Performance (IRP). Journal of Human Sciences, 13(1), 2277-2294.

State, O., \& Iorgulescu, M. C. (2014). The Impact of Management and OrAganizational Culture on Creativity in the Hotel Industry. Contemporary Approaches and Challenges of Tourism Sustainability, 16(8),1205-1222.

Sternberg, R. J. (2012). The assessment of creativity: An investment-based approach. Creativity Research Journal, 24(1), 3-12.

Tajeddini, K., Altinay, L., \& Ratten, V. (2017). Service innovativeness and the structuring of organizations: The moderating roles of learning orientation and inter-functional coordination. International Journal of Hospitality Management, 65, 100-114.

Tajfel, H., \& Turner, J. C. (1986). The Social Identity Theory of Intergroup Behavior. In S. Worchel \& W. Austin (Eds.), Psychology of Intergroup Relations (pp. 7-24). Chicago, IL: Nelson-Hall.

Thompson, J. (1967). Organizations in Action. New York: McGraw-Hill. .

Trifilova, A., \& Stamm, B. (2012). The Future of Innovation. London: Gower Publishing, Ltd.

Tsai, C. T., \& Lee, Y. J. (2014). Emotional intelligence and employee creativity in travel agencies. Current Issues in Tourism, 17(10), 862-871.

Turner, J. C., Hogg, M. A., Oakes, P. J., Reicher, S. D., \& Wetherell, M. S. (1987). Rediscovering the social group: A self-categorization theory. Cambridge, MA, US: Basil Blackwell.

Van Gelderen, M. W., Thurik, A. R., \& Bosma, N. (2006). Success and risk factors in the prestartup phase. Small Business Economics, 26(4), 319-335.

Vratskikh, I., Masa'deh, R., Al-Lozi, M., \& Maqableh, M. (2016). The Impact of Emotional Intelligence on Job Performance via the Mediating Role of Job Satisfaction. International Journal of Business and Management, 11(2), 69-91.

Wang, G., \& Netemeyer, R. G. (2004). Salesperson creative performance: conceptualization, measurement, and nomological validity. Journal of Business Research, 57(8), 805812.

Wong, C. S., \& Law, K. S. (2002). The effects of leader and follower emotional intelligence on performance and attitude: An exploratory study. Leadership Quarterly, 13 (3), 243274.

Yamazaki, Y., \& Kayes, D. (2004). An experiential approach to cross-cultural learning: A review and integration of competencies for successful expatriate adaptation. Academy of Management Learning and Education, 3(4), 362-379. 
Zimmerman, B. J., \& Paulsen, A. S. (1995). Self-monitoring during collegiate studying: An invaluable tool for academic self-regulation. New directions for teaching and learning, 1995(63), 13-27. 